\title{
INCIDÊNCIA DE HIPOTIREOIDISMO CONGÊNITO IDENTIFICADOS NO TESTE DO PEZINHO E SEU IMPACTO NO PROCESSO DE EDUCAÇÃO EM SAÚDE.
}

Karine Gomes Borguetti Fulaneti. SMS de Aparecida de Goiânia/Efermeira, graduada pela Universidade Salgado de Oliveira - karinefulanetti@ hotmail.com

Joselina Leite. Faculdade Salgado de Oliveira/Efermeira, graduada pela Universidade Salgado de Oliveira. - joselina.leite03@ hotmail.com

Marcos Cesar. Bombeiro Militar/ Enfermeiro, membro do grupamento de resgate préhospitalar- marcoscesarbm@gmail.com

Marielle Sousa Vilela. SMS de Aparecida de Goiânia/Enfermeira, Especialista em Saúde do Trabalhodor e coordenadora do programa de vasectomia da Prefeitura de Aparecida de Goiânia - mariellesv@gmail.com

Regis Rodrigues Santana. Faculdade Salgado de Oliveira/ Enfermeiro Especialista em UTI, Docente do Curso de Enfermagem da Universidade Salgado de Oliveira regissantana@hotmail.com

Milton Junio Candido Bernardes. Escola de Saúde Pública SESGO/Enfermeiro, Mestre em ciências farmacêuticas pela Universidade Federal de Goiás e mestrando em terapia intensiva pela Sociedade Brasileira de Terapia Intensiva - milton.bernardes@ gmail.com

RESUMO Estudo descritivo com abordagem quantitativa que teve como objetivos levantar a incidência do Hipotireoidismo Congênito (HC) região leste do município de Goiânia -GO e verificar os registros nos livros do Programa Nacional de Triagem Neonatal (PNTN) referentes ao HC bom como seu impacto no processo de educação em saúde. Os dados foram coletados em duas unidades básicas de saúde, utilizou-se um roteiro estruturado com perguntas fechadas como instrumento de coleta. Foram avaliados 2015 registros, o resultado revelou que 765 (37,96\%) não constavam dados referentes ao HC, encontravam-se incompletos. Os resultados apontaram a importância do enfermeiro no PNTN e a necessidade de investir na capacitação e educação continuada dos profissionais responsáveis pela triagem neonatal.

Palavras chaves: enfermagem. hipotireoidismo Congênito. triagem neonatal. Educação em saúde

\section{CONGENITAL HYPOTHYROIDISM IMPLICATIONS OF IDENTIFIED IN PKU TEST AND ITS IMPACT ON HEALTH EDUCATION PROCESS.}

ABTRACT: Descriptive study with a quantitative approach that aimed to raise the incidence of Congenital Hypothyroidism $(\mathrm{CH})$ region east of the city of Goiania $\mathrm{GO}$ and check the records in the books of the National Neonatal Screening Program (PNTN) for the HC good as its impact on the process health education. Data were collected in two basic health units, used a script structured with closed questions as collection instrument. We evaluated 2015 records, the result showed that $765(37.96 \%)$ were not included data for the HC, they were incomplete. 
The results showed the importance of nurses in PNTN and the need to invest in training and continuing education for professionals responsible for neonatal screening.

Key-words: nursing. congenital hipotireoidismo. neonatal nelection. health education

\section{Introdução}

Do vocabulário francês triage, o termo triagem significa separação, seleção de um grupo, ou mesmo escolha de inúmeros elementos. Em Saúde Pública o termo significa a realização de testes aplicados em uma população ou em um grupo de indivíduos que tem grande probabilidade de desenvolverem determinadas doenças (BRASIL, 2004).

Triagem Neonatal (TN) ou o "teste do pezinho" como é conhecido popularmente é um conjunto de exames realizados no recém-nascido $(\mathrm{RN})$ de preferência entre o $3^{\circ}$ e $5^{\circ}$ dia de vida, com o objetivo de detectar precocemente doenças genéticas e infecciosas que geralmente não apresentam sinais e sintomas após o nascimento. Por isso a necessidade de coletar as gotas de sangue do calcâneo do RN logo nos primeiros dias, para que seja possível identificar a doença e intervir precocemente instituindo o tratamento antes que a doença se manifeste e possa causar danos irreversíveis (STRANIERI, 2007).

"Só se entende como Triagem Neonatal quando todas as ações colaboram para a promoção da saúde da criança e o bem-estar da família" (FRANÇA; DOMINGOS, 2008).

Segundo o Estatuto da Criança e do Adolescente (ECA)- Lei -8069/13/07/90 - toda criança tem direito a vida e a saúde, mediante políticas sociais públicas que garantam o desenvolvimento com saúde, harmonia e dignidade para o seu desenvolvimento. De acordo com o artigo 10, parágrafo $3^{\circ}$ "proceder a exames visando ao diagnóstico e terapêutica de anormalidades do metabolismo do recém-nascido, bem como prestar orientações aos pais", deixando explícito a obrigatoriedade do teste do pezinho, em todos os nascidos vivos (BRASIL, 1990).

No final da década de 50 nos Estados Unidos, o biólogo Robert Guthrie através de estudos sobre a prevenção da doença mental, adaptou um método para identificar erros inatos no metabolismo, onde através de sangue coletado do $\mathrm{RN}$ e colocado em papel filtro, realizavam o diagnóstico precoce da fenilcetonúria (LACERDA; SILVA, 2003).

No dia 6 de junho do ano de 2001 através da Portaria Ministerial GM/MS n 822, o Ministério da Saúde (MS) criou o Programa Nacional de Triagem Neonatal (PNTN) que regulamenta a detecção precoce das doenças genéticas: Fenilcetonúria, Hipotireoidismo Congênito (HC), Hemoglobinopatias e Fibrose Cística (BRASIL, 2004). 
Devido a diversidade dos Estados o PNTN é organizado nas fases I( Fenilcetonúria e Hipotireoidismo Congênito), fase II (Fenilcetonúria, Hipotireoidismo Congênito, Doenças Falciformes e outras Hemoglobiopatias) e fase III( Todas as citadas acima mais Fibrose Cística), encontrando-se o Estado de Goiás na fase II(APAE, 2008). A Associação dos Pais e Amigos dos Excepcionais (APAE- Anápolis) é considerada pelo MS o único Serviço de Referência em Triagem Neonatal (SRTN) a realizar gratuitamente o teste do pezinho na rede pública de saúde no estado de Goiás (APAE, 2008).

Dentre os distúrbios triados o Hipotireoidismo Congênito (HC) é uma patologia que se for diagnosticada e tratada precocemente apresenta excelente prognóstico, onde as crianças se beneficiarão com a prevenção da doença mental (APAE, 2008).

Setian, (2007) define o HC como um distúrbio caracterizado pela deficiência ou ausência dos hormônios tireoidianos (T3 e T4), é classificado em primário, secundário e terciário, conforme a sua localização. Outro elemento fundamental é o iodo que é essencial para a síntese dos hormônios tireoidianos.

Há estimativa de que 1571 milhões de pessoas em 118 países encontram-se em carência de iodo em menor ou maior grau, tornando-se um problema de saúde pública com consequência danosa ao desenvolvimento social, econômico e mental da população em risco. Dentre os efeitos deletérios acarretados pela deficiência de iodo é o Retardo Mental o de maior impacto para o feto, recém-nascido, criança na fase escolar, adolescência e idade adulta, além da notada queda da fertilidade da população feminina jovem e, aumento da mortalidade perinatal e infantil (KNOBEL; NETO, 2004).

Os hormônios tireoidianos são fundamentais para o desenvolvimento do Sistema Nervoso Central (SNC), e a deficiência desses hormônios na vida fetal e no RN pode levar a falta de maturação dos tecidos podendo provocar lesões neurológicas irreversíveis (STRANIERI, 2007).

Segundo Souza; Schwartz; Giugliani, (2002) “em alguns casos, sinais e sintomas como icterícia neonatal prolongada, constipação, letargia, pele seca, dificuldades alimentares, língua protusa, hérnia umbilical podem estar presentes desde os primeiros dias de vida".

Contudo, conforme relata Stranieri, (2007) esses sinais e sintomas aparecem geralmente após o segundo mês de vida, quando em geral os danos cerebrais já estão ocorrendo. 
É necessário frisar a importância do diagnóstico laboratorial, uma vez que os sinais e sintomas nem sempre se apresentam de modo evidente, o que acaba dificultando o diagnóstico clínico podendo perder grande tempo para a instituição do tratamento, que ocorre com a reposição do hormônio tireoidiano, administrando-se o Hormônio de escolha a levotiroxina (SETIAN, 2007).

O interesse de aprofundar no assunto foi a repercussão do desenvolvimento da doença mental e o pouco conhecimento relacionado ao $\mathrm{HC}$, a partir desenvolver esta pesquisa com o intuito de levantar dados sobre a incidência do HC na Região Leste de Goiânia-GO a qual foi escolhida por apresentar um população demográfica de quantidade expressiva.

É necessário a verificação da incidência do $\mathrm{HC}$ e ter uma análise crítica dos resultados e consequências, visto que segundo dados do Ministério da Saúde, 2007 a região centro-oeste apresentou um total de 87 casos de $\mathrm{HC}$, dos quais 45 (51,72\%) foram diagnosticados em Goiás (BRASIL, 2007).

A enfermagem tem papel importante e intransferível no PNTN por ser quem mais interage com o binômio mãe e filho. Cabe ao profissional a responsabilidade de desenvolver um bom trabalho, derrubando tabus e mitos, visando o processo de educação em saúde dos indivíduos que estão envolvidos neste processo além de aproveitar a facilidade que o profissional enfermeiro possui de ser educador e enaltecer a importância do teste do pezinho para a sociedade (LACERDA; SILVA, 2003).

Outra função que é importante para a enfermagem segundo Caixeiro; Dargam; Thompson, (2008) é a elaboração de registros com qualidade e ética, porém observa-se na prática diária negligência por parte de muitos profissionais. Anotações escassas e incompletas dificultam a análise das mesmas, não alcançam a finalidade proposta e deixam dúvidas quanto a logicidade das informações.

Assim objetiva-se com esta pesquisa, levantar a incidência de Hipotireoidismo Congênito registrados em duas unidades de saúde bem como o processo de educação em saúde.

\section{Materiais e Métodos}

Estudo exploratório descritivo de abordagem quantitativa realizado nos registros dos livros do PNTN no período de janeiro 2006 a dezembro de 2008. Estudo descritivo segundo 
Polit; Beck; Hungler, (2004) tem como objetivo primordial a descrição das características de determinada população ou fenômeno ou, então, o estabelecimento de relações entre as variáveis. Teve como cenário duas instituições de saúde da Rede Pública, situado na Região Leste do município de Goiânia, Estado de Goiás. A região Leste foi escolhida devido o número expressivo de habitantes (106.966,00 habitantes) segundo dados do IBGE 2000, contendo 10 unidades de saúde para atender esta demanda, e o critério para escolha das unidades se deu forma aleatória através de sorteio, e como critério de exclusão dados constados nos livros, que foram anteriores a 2006 e com informações pertinentes a outras patologias. A amostra para realização deste trabalho foi a pesquisa nos livros de registros das Unidades Básicas de Saúde.

Foi construído um instrumento de coleta de dados pelos autores e validado por três pesquisadores experts na área. Como instrumento para coleta de dados utilizou-se um roteiro estruturado com perguntas fechadas contendo 8 questões, com objetivo de identificar a incidência de $\mathrm{HC}$ como esta o registro do HC. Utilizamos as seguintes perguntas: Positividade para o HC; Ano de coleta das amostras de sangue; Período após nascimento para coleta; como esta o preenchimento dos registros nos livros; Qual a dosagem dos Hormônios Tireoidianos encontrados; A idade da mãe da criança; A letra de preenchimento dos registros; A frequiência em que ocorre o envio das amostras para o Serviço de Referência em Triagem Neonatal (SRTN).

A coleta de dados ocorreu nas unidades, sendo agendadas com antecedência, pela diretoria do local.

Este estudo seguiu as Diretrizes da Resolução 196/96, acerca dos princípios éticos de pesquisa realizada com seres humanos, obtendo-se a autorização para realização da pesquisa, após ter sido avaliado e apreciado pelo Comitê de Ética em Pesquisa do Hospital Materno Infantil, sob o protocolo número 002/09.

Posterior a coleta dos dados os dados foram separados por unidade de saúde, ano de coleta, e analisando cada pergunta separadamente, para contagem, tabulação e a construção de gráficos e tabelas utilizando o programa Microsolf Office Excel 2003.

\section{Resultados}


A pesquisa abrangeu um quantitativo de 2015 registros onde, 506 foram coletados na unidade A, 1509 na unidade B o que é demonstrado no gráfico I.

Gráfico I. Distribuição do total de registros coletados nas unidades A e B -Goiânia-Goiás-2009.

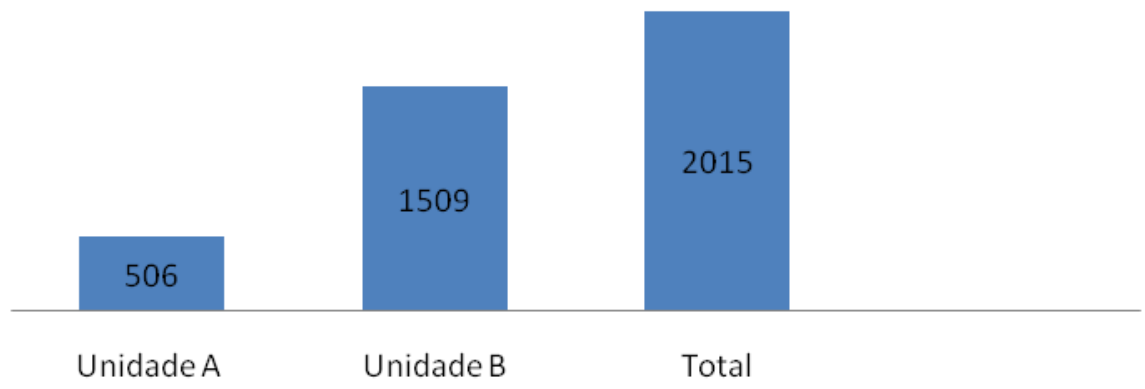

Fonte: Livros de registros da unidade A e B. Elaboração: Joselina V. Leite; Karine G. Fulanetti.

Os dados foram analisados separadamente de acordo com cada unidade, e para cada item levantado no instrumento de coletas de dados foi criado um gráfico para interpretação dos mesmos.

Análise dos dados da Unidade A.

Dos 2015 registros, $506(25,12 \%)$ foram coletados na Unidade A, sendo no ano de 2007 (102 registros) e no ano de 2008 (404 registros).

No ano de 2006 não foi possível a coleta de registro, devido reforma da estrutura física da unidade, perdeu-se o arquivo. 
Gráfico II. Registros coletados na unidade A no período de 2006 a 2008- Goiânia- Goiás- 2009.

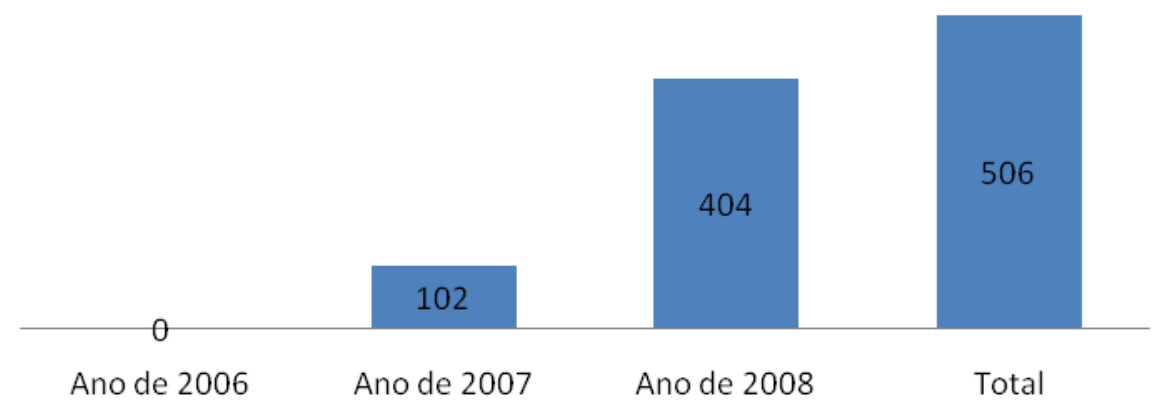

Fonte: Livros de registros da unidade A . Elaboração: Joselina V. Leite; Karine G. Fulanetti.

Dos 506 casos $448(88,53 \%)$ apontou negatividade para o HC e $58(11,46 \%)$ dos registros estavam sem resultados.

Gráfico III. Dados referentes à positividade para Hipotireoidismo Congênito- Goiânia- Goiás- 2009.

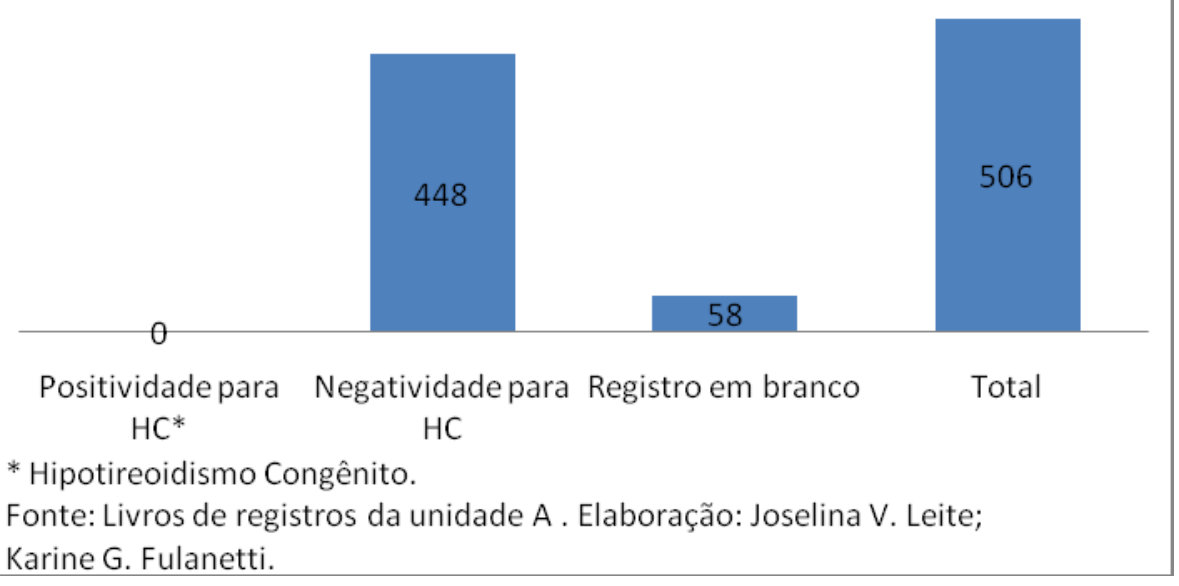

Em relação ao período de coleta após o nascimento verificou-se que 4 (0,7\%)foram coletados antes do $3^{\circ}$ dia de vida, $266(53 \%)$ coletados entre o $3^{\circ}$ e $7^{\circ}$ dia de vida, 234 (46\%) acima do $7^{\circ}$ dia de vida e $2(0,3 \%)$ cujo o registro estava em branco.

Tabela I.Distribuição dos registros de acordo com o período de coleta após nascimento -

Goiânia- Goiás-2009 


\begin{tabular}{ccc}
\hline Período de coleta & $\mathbf{N}^{\circ}$ & \% \\
\hline Antes do $3^{\circ}$ dia de vida & 4 & $0,70 \%$ \\
Entre o $3^{\circ}$ e $7^{\circ}$ dia de vida & 266 & $53,00 \%$ \\
Acima do $7^{\circ}$ dia de vida & 234 & $46,00 \%$ \\
Registro em branco & 2 & $0,30 \%$ \\
Total & 506 & $100 \%$ \\
\hline
\end{tabular}

Fonte: Livros de registros da unidade de saúde A.

Elaboração: Joselina Vieira Leite; Karine Gomes Fulanetti.

Dos 506 registros coletado na Unidade A foram verificados que $434(85,77 \%)$ dos registros estavam completos e $72(14,23 \%)$ estavam incompletos.

\section{Gráfico IV. Análise dos registros quanto ao peenchimento- Goiânia- Goiás- 2009.}

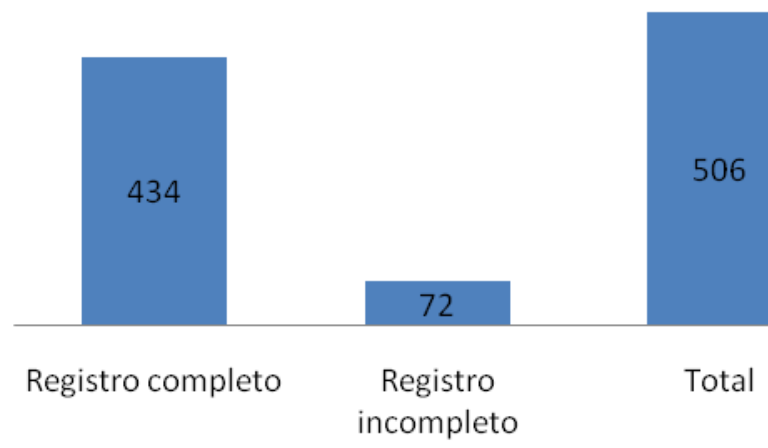

Fonte: Livros de registros da unidade A . Elaboração: Joselina V. Leite; Karine G. Fulanetti.

Analisando quanto ao dado referente à letra de preenchimento dos registros, 438 $(86,57 \%)$ estavam legíveis e $68(13,43 \%)$ encontravam-se parcialmente legível e ilegível $(0 \%)$. 


\section{Gráfico V. Análise dos registros quanto à letra de peenchimento- Goiânia- Goiás- 2009.}

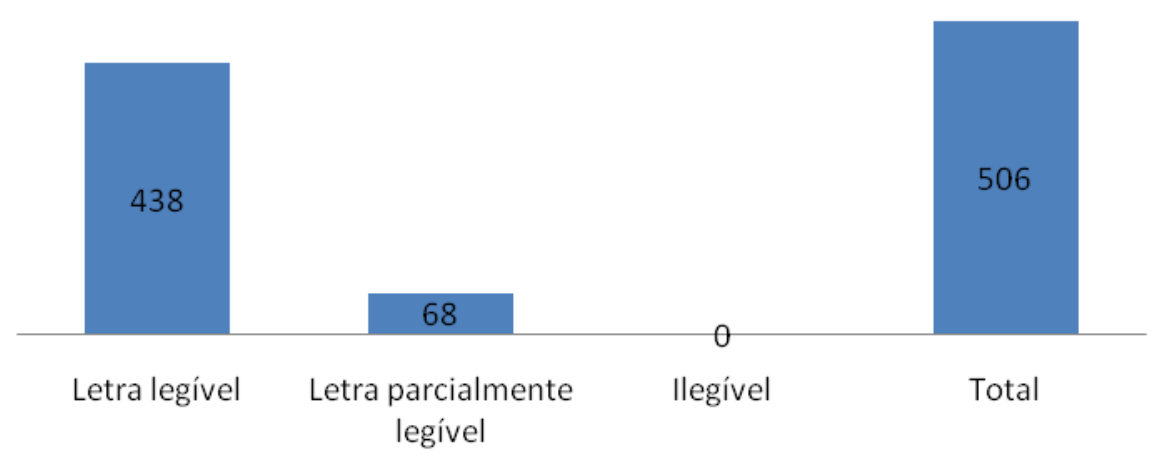

Fonte: Livros de registros da unidade A . Elaboração: Joselina V. Leite; Karine G. Fulanetti.

Análise dos dados da Unidade B.

Dos 2015 registros, 1509 (74,88\%) foram coletados na Unidade B, encontrando-se no ano de 2006, um quantitativo de 418 registros (27,70\%), em 2007 foram coletados 575 registros $(38,10 \%)$ e em 2008 um número de $516(34,20 \%)$.

Os 418 registros coletados no ano de 2006*, não foi possível a análise, pois os mesmos neste período eram de responsabilidade do laboratório onde não era anotado os resultados, eles estavam totalmente incompletos, constando apenas a realização do teste, ficando assim excluído das análises subsequentes. 
REVISTA ELETRONICA

Ithimiaiaus REF HEकाloxis

Gráfico VI. Registros coletados na unidade B no período de 2006 a 2008 - Goiânia- Goiás- 2009.

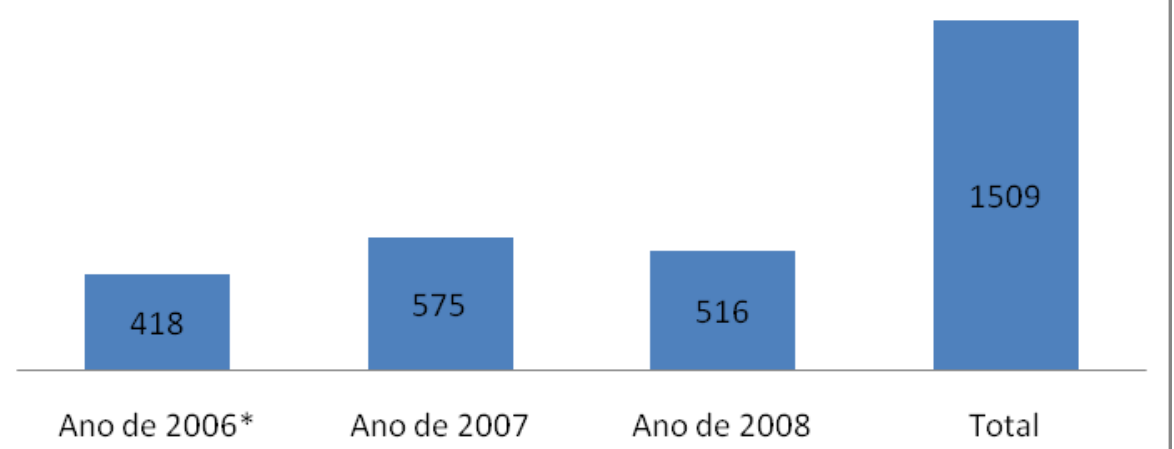

Fonte: Livros de registros da unidade B. Elaboração: Joselina V. Leite; Karine G. Fulanetti.

* Não analisados.

A soma do ano de 2007 e 2008 aponta um total de de 1091, onde $802(73,50 \%)$ apresentaram negatividade para o HC e 289 (26,50\%) dos registros estavam sem resultados

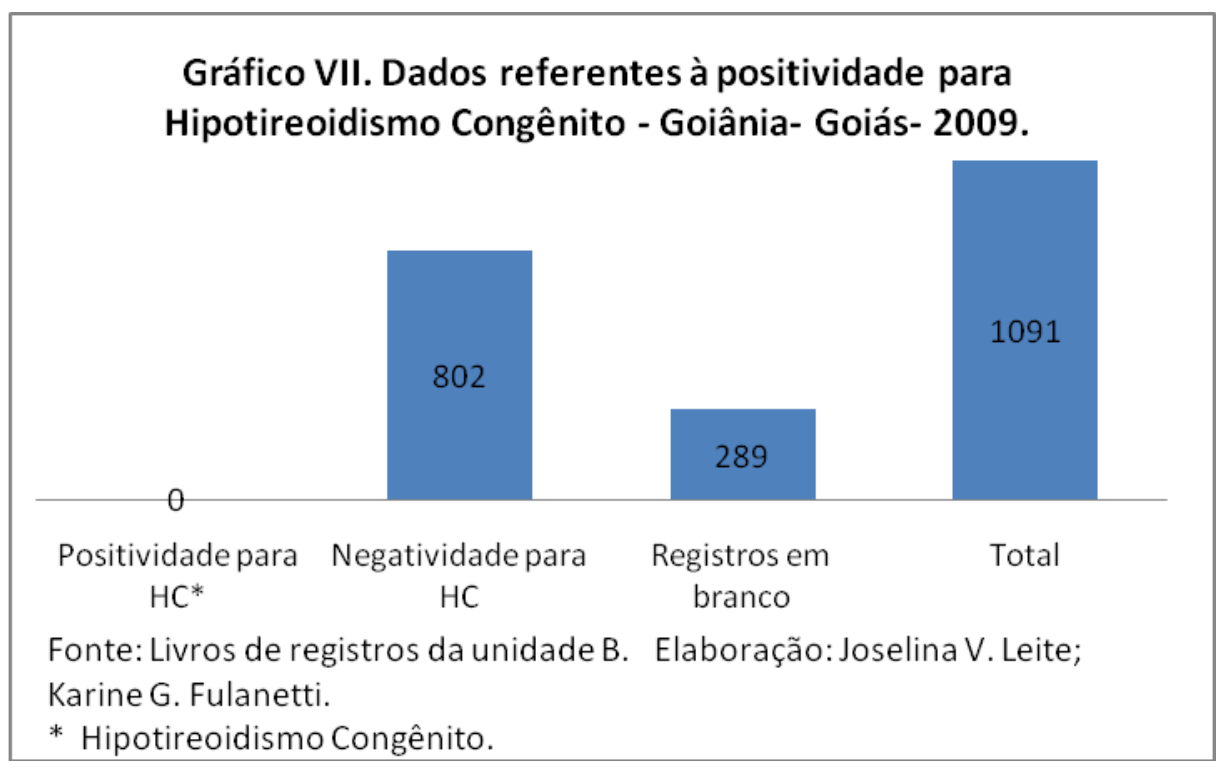

O período de coleta após o nascimento foi de 24 (2,20\%) coletados antes do $3^{\circ}$ dia de vida, $528(48,40 \%)$ coletados entre o $3^{\circ}$ e $7^{\circ}$ dia de vida, $516(47,30 \%)$ num período acima de 7 dias e $23(2,10 \%)$ cujo registro estava em branco. 
Tabela II. Distribuição dos registros de acordo com o período de coleta após nascimento -Goiânia- Goiás-2009.

\begin{tabular}{c|c|c}
\hline Período de coleta & $\mathbf{N}^{\circ}$ & $\%$ \\
\hline Antes do $3^{\circ}$ dia de vida & 24 & $2,20 \%$ \\
Entre o $3^{\circ}$ e $7^{\circ}$ dia de vida & 528 & $48,40 \%$ \\
Acima de $7^{\circ}$ dia vida & 516 & $47,30 \%$ \\
Registro em branco & 23 & $2,10 \%$ \\
Total & 1091 & $100 \%$ \\
\hline
\end{tabular}

Fonte: Livros de registros da unidade de saúde B.

Elaboração: Joselina Vieira Leite; Karine Gomes Fulanetti.

Dos 1091 foram verificados que $811(74,35 \%)$ dos registros estavam completos e 270 $(24,70 \%)$ estavam parcialmente completos e $10(0,91 \%)$ incompletos.

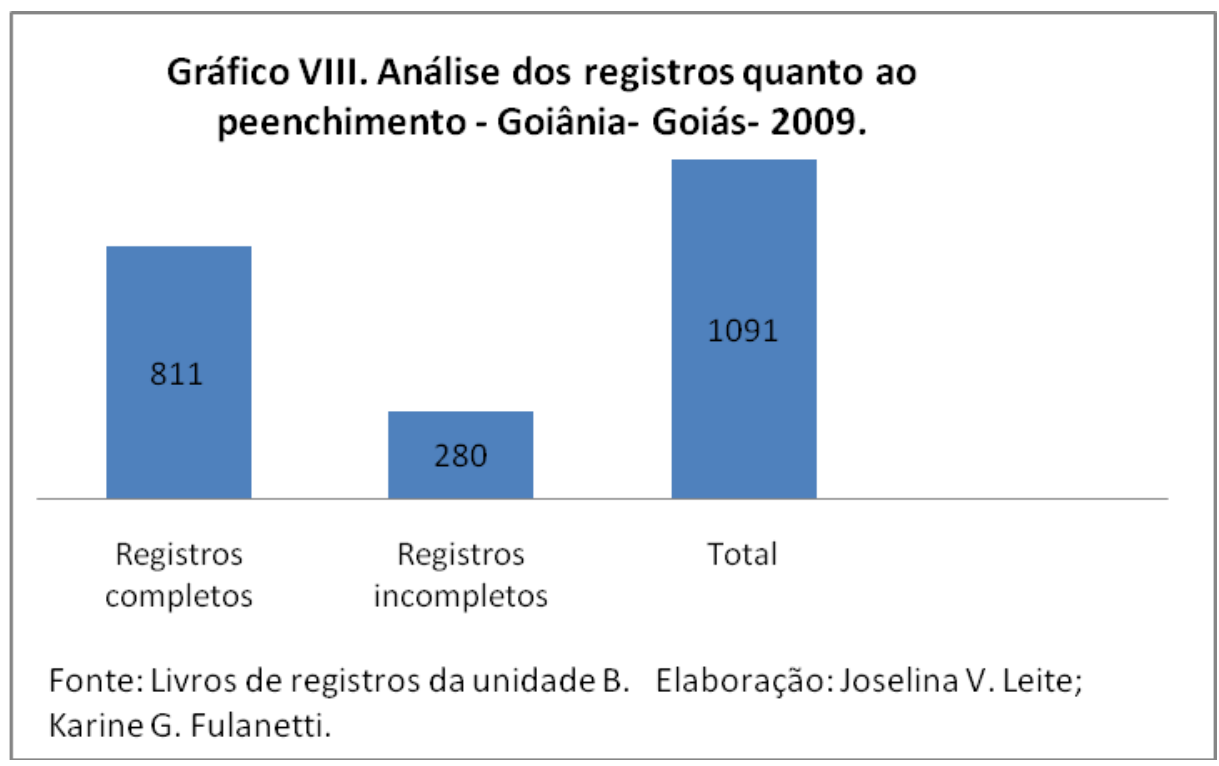

Analisando quanto ao dado referente a letra de preenchimento do registros 957 $(87,71 \%)$ estavam legíveis e 134 (12,29\%) encontravam-se parcialmente legíveis e ilegível $(0 \%)$. 


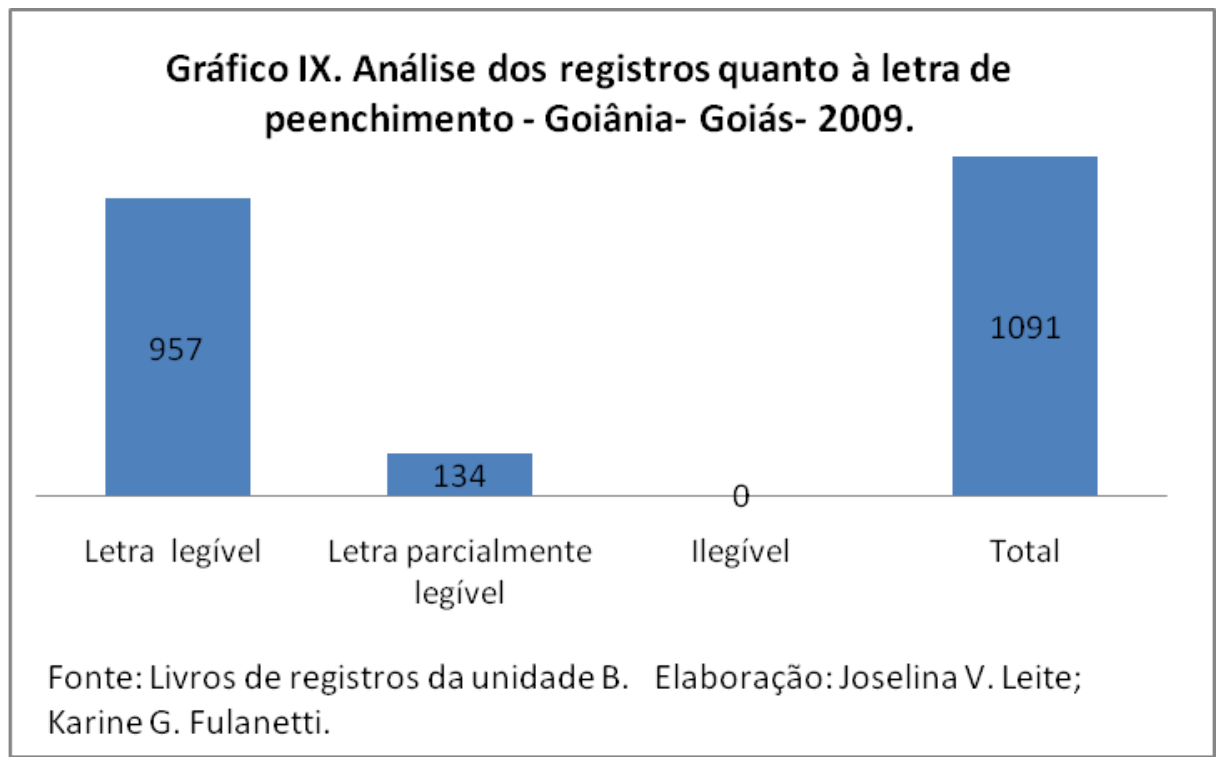

\section{Discussão}

Diante dos resultados obtidos neste estudo levantamos um quantitativo expressivo de registros, porém não conseguimos alcançar um dos objetivos que era a verificação da incidência de $\mathrm{HC}$, o que é justificado pela falta de anotação por parte dos profissionais, e comprovado, pois, dos 2015 registros coletados nas duas unidades 765 (37,96\%) registros estavam sem dados referentes a positividade ou negatividade para o HC. Caixeiro, Dargam, Thompson, (2008) em seu trabalho relata que é papel da enfermagem a elaboração de registros com qualidade, que a falta de anotações e dados dificultam a compressão e análise das mesmas.

Em relação ao período de coleta das amostras dos 2015, foram analisados 1597 pois como já mencionado anteriormente 418 referentes ao ano de 2006 da unidade B não serviram como objeto de análise pois encontravam totalmente incompletos e não foi possível analisar o quesito período de coleta. Foram coletados 25 (1,57\%) registros em branco, 28 (1,75\%) antes do $3^{\circ}$ dia de vida, o que são consideradas amostras precoces que podem fornecer resultados não confiáveis, pois é necessário que a criança tenha ingerido proteína ( através do aleitamento) suficiente para serem detectadas de forma segura na triagem da fenilcetonúria . Foram coletados $794(49,72 \%)$ registros entre o $3^{\circ}$ e $7^{\circ}$ dia de vida , que é a faixa etária considerada ideal pelo PNTN e observados que 750 (46,96\%) registros equivalem a coleta realizada num período superior a 7 dias o que contradiz as diretrizes do Programa, porém a 
realização do teste é um direito da criança mesmo fora do período preconizado. Setian, (2007) relata em seu trabalho a importância da realização do teste do pezinho no período ideal objetivando o diagnóstico precoce, para que ocorra a intervenção logo nos primeiros dias de vida evitando-se lesões irreversíveis e danos para o Desenvolvimento Neuropsicomotor (DNPM). Stranieri, (2007) pressupõe a necessidade de investir na capacitação, sensibilização e educação continuada dos profissionais responsáveis pela coleta bem como orientações aos pais e responsáveis quanto a importância da realização do teste do pezinho no período ideal.

Analisando os registros quanto ao quesito completo e incompleto, $1245(61,78 \%)$ estavam completos e 770 (38,22\%) encontravam-se incompletos em relação a dados referentes ao resultado, data de nascimento da criança e data de coleta, lembrando que estão inclusos nos registros incompletos os 418 referentes ao ano de 2006, por se enquadrarem dentro do quesito incompleto.

Um registro de qualidade instiga na equipe multidisciplinar o interesse em consultálos, pois os mesmos constituem importantes fontes de informação (CAIXEIRO; DARGAN; THOMPSON, 2008), deixando assim explícito a necessidade dos profissionais de saúde, preencher os registros completamente, não deixar nenhum dado em branco.

$\mathrm{O}$ artigo $\mathrm{n}^{\circ} 41$ do Código de Ética dos Profissionais de Enfermagem ressalta a importância e a necessidade dos registros completos "Prestar informações, escritas e verbais, completas e fidedignas necessárias para assegurar a continuidade da assistência”, reafirmando a responsabilidade e dever dos profissionais quanto a elaboração de registros com qualidade, informações claras, objetivas e completas, lembrando que os registros constituem um importante instrumento da qualidade da assistência e o enfermeiro enquanto líder e supervisor tem o papel de orientar as atividades realizada pela sua equipe.

Vale lembrar que a atuação do enfermeiro dentro dos serviços de saúde são reflexos do que os mesmos tiveram na academia, ainda a importância dos registros estão envolvidas diretamente com processo de educação continuado nos serviços de saúde.

Referente a letra de preenchimento dos registros 1395 (87,35\%) estavam legíveis e $202(12,65 \%)$ estavam parcialmente legíveis. Segundo Bemmel (apud) Caxeiro (2008) o registro de enfermagem é um mecanismo de comunicação entre a equipe multidisciplinar, documento legal para cliente, profissional e instituição, além de ser fonte de dados para pesquisas e indicador da qualidade da assistência prestada. Ocorre também a necessidade de preencher os registros com letra legível e preferencialmente de forma, utilizar caneta 
estereográfica para garantir uma boa leitura, evitar uso de abreviaturas para que assim não ocorra erros e duplicidade de informações.

O envio das amostras para o Serviço de Referência em Triagem Neonatal (SRTN) ocorre semanalmente na Unidade A e a cada 2 dias na Unidade B. O Ministério da Saúde deixa claro: "È sua responsabilidade que as amostras não fiquem retidas na unidade por um período superior a 5 dias úteis. Elas podem se tornar velhas pra serem analisadas" (BRASIL, 2004).

Em relação a ficha de coleta apesar de simples é um documento legal, que a preenche é responsável pelas informações contidas ali, o que é ressaltado pelo ministério da saúde:

\begin{abstract}
A ficha de coleta é um documento legal. Quem o preenche é o responsável pela precisão das informações ali contidas. As atividades no posto de coleta, apesar de serem consideradas muito simples, são de fundamental importância para o Programa de Triagem Neonatal. O posto de coleta é a porta de entrada do programa.. Sua organização e as informações de identificação ali coletadas são críticas e essenciais para a localização das crianças que necessitam de atenção especial (BRASIL, 2004).
\end{abstract}

Nem sempre em uma pesquisa consegue-se alcançar os objetivos propostos, pois muitas vezes no decorrer do estudo são encontradas limitações que impossibilitam o alcance de algum objetivo, como a falta de dados, anotações incompletas, falta de legibilidade, perdas de arquivos e outros.

\title{
Conclusão
}

Os resultados deste estudo apontaram a importância do enfermeiro no PNTN, desde o processo de educação em saúde e suas respectivas orientações que ocorrem no pré-natal sobre a importância do teste, as doenças triadas, a realização da coleta no período ideal, a importância do diagnostico precoce bem como a necessidade de supervisão do enfermeiro a estimular a equipe no desenvolvimento de uma assistência de qualidade, além de proporcionar um ambiente e condições favoráveis para o aperfeiçoamento técnico e científico da equipe responsável pela triagem neonatal através de cursos e palestras que estão inseridas dentro do calendário de educação permanente/continuada das equipes de saúde.

De acordo com o resultado demonstrado não conseguimos alcançar um dos objetivos que era levantar a incidência do $\mathrm{HC}$ na região leste, porem 38,21\% dos registros 
encontravam-se incompletos referentes a vários dados deixando questionamento quanto a ocorrência ou não de casos da doença naquela região. Esse fato nos remete a importância da atuação da enfermagem ao registrar as ações desenvolvidas, um registro com dados incompletos interferem na assistência, causam duplicidade, interfere nos resultados de estudos pois, os mesmos servem de material de referência para ensino e pesquisa e do processo de educação como um todo, não esquecendo que o registro é um indicativo da qualidade da assistência prestada. Dentre os registros encontramos rasuras, falta de sequência, espaços em branco, falta de assinatura do profissional, uso de corretivo, tudo isso nos levou a questionar a atuação do papel do enfermeiro em quanto líder da equipe, pois sabe-se que é o supervisor dos demais profissionais cabendo-lhe a função de estimular e direcionar a equipe no desenvolvimento de um trabalho de qualidade em todas as etapas da atividade proposta.

Após a analise dos dados através dos livros de registros das unidades percebemos que para melhorar a assistência prestada e registrada nos livros de controle seria necessário um padronização quanto aos dados registrados e coletados conforme sugestão do Ministério da Saúde no Manual de Triagem Neonatal na página 33, bem como reuniões periódicas com treinamento para estes profissionais remetendo assim a importância de se aplicar o processo de educação permanente em saúde nos serviços que abrangem o teste do pezinho.

As pesquisas que envolvem a área da saúde, especialmente a enfermagem, são tão importantes quanto necessárias porque além de demonstrarem resultados apontam soluções, abrem caminhos para novas pesquisas e novas concepções e fundamentam a nossa prática.

\section{Referências}

1. APAE - Associação dos Pais e Amigos dos Excepcionais. Anápolis - GO. Disponível em: <htttp://apaeaps.org.br.> Acessado em: 15/09/ 2008.

2. BRASIL. Lei Federal N. ${ }^{\circ} 8069$ de 13 de julho de 1990. Estatuto da Criança e Adolescente: Do Direito à Vida e à Saúde. Inciso III do artigo 10 ${ }^{\circ}$. Brasília-1990. Disponível em: http://www.planalto.gov.br/ccivil/LEIS/L8069.htm Acessado em 02/10/ 2008.

3. BRASIL. Ministério da Saúde. Indicadores do Programa Nacional de Triagem Neonatal. 2007. Disponível

em: $<$ http://portal.saude.gov.br/portal/arquivos/pdf/INDICADORES_TRIAGEM_NEONATALpd f> Acessado em: 22/09/2008. 
4. BRASIL. Ministério da Saúde. SAS/CGAE. Manual de Normas Técnicas e Rotinas Operacionais do Programa Nacional de Triagem Neonatal.Brasil (DF); 2004.Disponível em: <http:// www.saude.gov.br> Acessado em: 03/09/2008.

5. CAIXEIRO, S. M. O.; DARGAM, B.; THOMPSON, G. N. Comunicação Escrita: importância para os profissionais de enfermagem nas salas de pré-parto. Rev. enferm. UERJ v.16, n.02, p. 218-223, Rio de Janeiro, abr/jun, 2008.

6. Conselho Federal de Enfermagem [homepage]. Resolução 311. Aprova a Reformulação do Código de Ética dos Profissionais de Enfermagem, 2007. Disponível em: http://www.corengo.org.br. Acessado em:20/01/2009.

7. Diretrizes e normas regulantares de pesquisa envolvendo seres humanos. Resolução n¹96/96. Brasília (DF): Ministério da Saúde; 2000.

8. FRANÇA, S. N.; DOMINGOS, M. T. Triagem Neonatal de Hipotireoidismo Congênito: Novas Conquistas...Novos desafios... Arq. Bras. Endocrinol. Metab, v. 52, n. 4, p. 579-580, 2008. Disponível em: <http://www.scielo.br. > Acessado em: 03/09/2008.

9. IBGE- Instituto Brasileiro de Geografia e Estatística.Disponível em: <http://www.ibge.gov.br/cidadesat/topwindow.htm?1> Acessado em 02/10/ 2008

10. IBGE- Instituto Brasileiro de Geografia e Estatística. Censo Demográfico 2000.

11. KNOBEL ,M.; NETO,G.M. Moléstias Associadas à carência Crônica de Iodo. Arq. Bras. Endocrinol. Metab, v.48, n.01, p.53-61, Fevereiro, 2004. Disponível em: <http://www.scielo.br $>$. Acessado em:20/09/2008.

12. LACERDA, M. R.; SILVA, M. B. G. M. "Teste do Pezinho." Por que coletar na alta hospitalar? Revista Eletrônica de Enfermagem, v.5, n.2, p. 60-64, 2003. Disponível em: <http:// www.fen.ufg.br/revista.> Acessado em: 03/09/2008.

13. MINAYO, M.C. Pesquisa Social: Teoria, Método e Criatividade. $23^{a}$ ed. Petrópolis (RJ):Vozes; 1993.

14. POLIT, D. F.; BECK, C. T.; HUNGLER, B. P. Fundamentos de Pesquisa em Enfermagem: Métodos, avaliação e utilização. $5^{\circ}$ edição. Porto Alegre: Artmed, 2004. p. $117 ; 250$.

15. SETIAN, N. Hipotireoidismo na criança: diagnóstico e tratamento. Jornal de Pediatria,v.83, n.5, p.209-216, Rio de Janeiro,2007. Disponível em: <http://www.scielo.br Acessado em: 26/08/2008.> 
REVISTA ELETRONICA

injeriatius

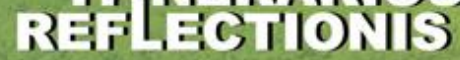

GRADUAC,AO/POS - GRADUACAO EMEDUCACAO UFG/REJ

16. SOUZA, C. F. M.; SCHWARTZ, I. V.; GIUGLIANI, R. Triagem Neonatal de distúrbios metabólicos. Ciência e Saúde Coletiva, v.7, n.1, p. 129-137, 2002. Disponível em $<$ http://www.scielo.br> Acessado em:29/08/2008.

17. STRANIERI, I. Avaliação da Implantação do Programa de Triagem Neonatal para Hipotireoidismo Congênito e Fenilcetonúria entre Usuários da Rede Pública. Estado de Mato Grosso, 2003-2004. Cuiabá- MT:UFMT, 2007. Disponível em: <http://cpd1.ufmt.br/isc2006/mestrado/index.php?option=com_docman\&task=doc_view\&gid $=23 \% 20->$ Acessado em:10/09/2008 